\title{
Body Temperature Detection and Data Collection during COVID-19
}

\author{
Wenhong $\mathrm{Yu}^{1, \mathrm{a}}$, Chenlu $\mathrm{Luo}^{1}$ and Kuan Wang ${ }^{2}$ \\ ${ }^{1}$ North China University of Technology, 100144, Beijing, China \\ ${ }^{2}$ China Railway Construction Group CO., LTD, Beijing 100131, China
}

\begin{abstract}
At present, COVID-19 is raging in many countries, which poses a great threat to people's life, health, social and economic development. Body temperature screening is very helpful for early detection of potential infected persons and blocking the spread of the epidemic. The paper mainly introduces the body temperature detection and data acquisition system, and designs a system with the function of non-contact temperature measurement and automatic data collection system. This system is suitable for the company or school where the flow of people is large and the temperature needs to be measured quickly, and upload information in real time.
\end{abstract}

\section{Research background}

A new type of corona virus pneumonia (COVID-19) was found in Wuhan, China in December 2019. Since then, confirmed and suspected cases have been reported elsewhere in the country, and start a primary response to major public health emergencies. COVID-19 patients with fever, fatigue, dry cough as the main symptoms. Body temperature can be used to screen suspected patients early, COVID-19 is an important prevention and control measures. ${ }^{[1]}$

At present, human body temperature is measured and recorded by traditional manual methods in most areas of our country. The traditional temperature collection method has the disadvantages of large measurement error, not timely feedback and large workload of statisticians.
With the development of modern technology, the intelligent, information and automation of temperature measuring equipment has become an urgent need.

\section{Temperature Detection and Data Collection System}

During the period of epidemic prevention and control, there are many kinds of temperature measurement methods and body temperature collection methods, among which the common systems are: infrared temperature detection door, face recognition thermometer, portable automatic infrared temperature screening instrument, etc.

Table 1. Epidemic prevention and control demand analysis

\begin{tabular}{|c|c|c|c|}
\hline & Epidemic prevention and control & Demand analysis & $\begin{array}{c}\text { Temperature measuring } \\
\text { instrument }\end{array}$ \\
\hline 1 & Flow density at the entrance & $\begin{array}{c}\text { Rapid Temperature Screening } \\
\text { requirements }\end{array}$ & Infrared thermometer \\
\hline 2 & Highly contagious virus & $\begin{array}{c}\text { Non-contact temperature } \\
\text { measurement requirements }\end{array}$ & Infrared thermometer \\
\hline 3 & Non-human target interference & $\begin{array}{c}\text { Face Detection and } \\
\text { Temperature Measurement } \\
\text { Requirements }\end{array}$ & $\begin{array}{c}\text { Face Recognition } \\
\text { Temature Measuring } \\
\text { Machine }\end{array}$ \\
\hline 4 & Repetition of temperature collection & $\begin{array}{c}\text { Automatic Data Acquisition } \\
\text { Requirements }\end{array}$ & $\begin{array}{c}\text { Temperature detection and } \\
\text { acquisition system }\end{array}$ \\
\hline
\end{tabular}

\footnotetext{
a yuwenhong@ncut.edu.cn
} 


\subsection{Infrared temperature detection door}

The infrared temperature detection door has a wide temperature measurement area, in the working environment $0^{\circ} \mathrm{C}-45^{\circ} \mathrm{C}$, the response time is less than 1 second, when the body temperature is abnormal, it can sound the alarm. In addition, infrared temperature detection door can be connected with computer, channel gate equipment, and can provide channel gate switch signal. It can be used for subway security inspection, railway station security inspection, mall security inspection and other occasions.

\subsection{Face Recognition Temperature Measuring Machine}

Face recognition temperature measuring machine built-in powerful AI chip, algorithm and computing power can complete face recognition within 200 milliseconds, and support occlusion recognition, abnormal body temperature automatic alarm, Once the body temperature exceeds the normal value, it will automatically alarm and prohibit traffic.

\subsection{Automatic Infrared Temperature Screening System}

Portable automatic infrared temperature screening instrument with tripod, suitable for high-speed exit car and other flexible temperature inspection, millisecond response, measurement accuracy up to $\pm 0.5^{\circ} \mathrm{C}$, the crowd of ultra-high temperature personnel automatic alarm, Automatic capture of abnormal personnel thermal image photos, can achieve senseless temperature measurement.

\section{Design of Body Temperature Detection and Data Acquisition System}

In order to realize the random unit personnel body temperature test and automatically arranged into a table with units as categories, the human body temperature detection and the collection system designed in this paper mainly includes three molecular function modules, specifically: the identification sub-module, the temperature detection sub-module, the data processing sub-module. The overall flow of the system is shown in figure 1 .

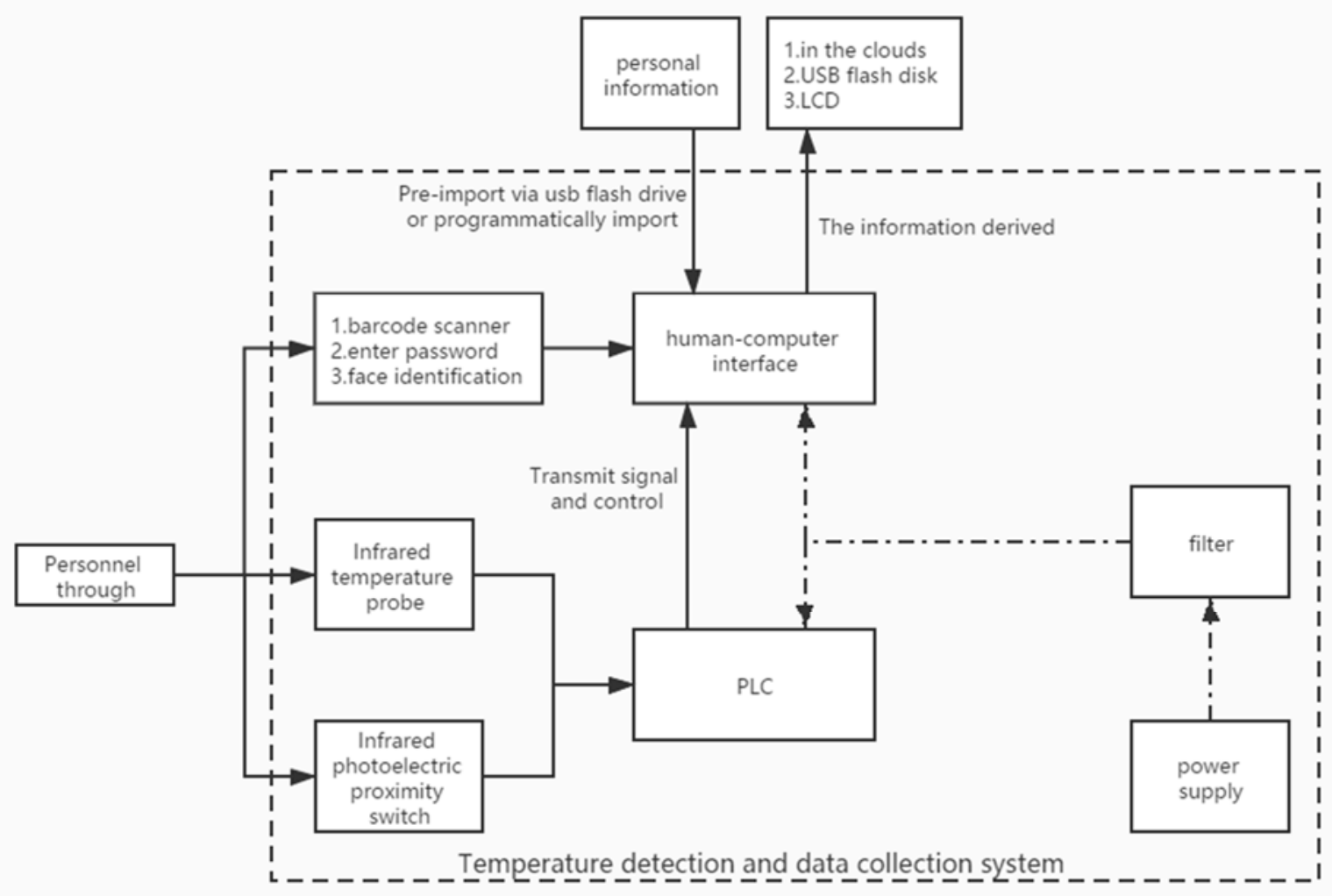

Figure 1. Flowchart of Temperature Detection and Acquisition System

\subsection{Identification sub-module}

Identification sub-module is an important part of body temperature detection and acquisition system. It provides identity information for data acquisition sub-module. Personnel should import information into the human-machine interface through USB flash disk or programming in advance. When the person passes through the $\mathrm{U}$ disk or programming, it can be scanned with a barcode scanner, input the exclusive password or face recognition, call the pre-import personnel information, identify and match, and achieve the purpose of collecting personnel information quickly. 


\subsection{Temperature detection sub-module}

The temperature detection sub-module is the main component of the temperature detection and acquisition system. [2] It provides temperature information for the data acquisition sub-module. When the personnel pass, the infrared photoelectric proximity switch is triggered and the infrared temperature probe temperature measurement function is turned on. After processing by programmable logic controller, the temperature information is transmitted and displayed in man-machine interface.

\subsection{Data-processing sub-module}

Data processing sub-module is the core part of temperature detection and acquisition system. Under the power supply of filter, programmable logic controller integrates identification and temperature detection results, displays personnel information and body temperature on man-machine interface. At the same time, the collected information is collected and stored in the memory of programmable logic controller and can uploaded to "cloud".

\subsection{System hardware composition design}

The hardware composition of temperature detection and data acquisition system includes photoelectric switch, man-machine interface, infrared temperature probe, filter, power supply, programmable logic controller. Its model and composition are shown in Table 2 below.

Table 2. Composition and function of system hardware

\begin{tabular}{|c|c|c|c|}
\hline & Component & Model & Purpose \\
\hline 1 & $\begin{array}{c}\text { Infrared photoelectric } \\
\text { proximity switch }\end{array}$ & $\begin{array}{c}\text { CHE } \\
\text { 18-30NA-B710E3F-DS30CA }\end{array}$ & $\begin{array}{c}\text { Control temperature sensor } \\
\text { activated }\end{array}$ \\
\hline 2 & Man-machine interface & 6AV6 648-0 CC11-3AX0 & $\begin{array}{c}\text { Recording and displaying } \\
\text { information }\end{array}$ \\
\hline 3 & Infrared temperature probe & SA50R4D & Measuring acquisition temperature \\
\hline 4 & Filter & DNF05-H-10A & $\begin{array}{c}\text { Maintain stable working condition } \\
\text { of power supply }\end{array}$ \\
\hline 5 & Power supply & CPSNT 48W 24V 2A & Provide energy \\
\hline 6 & $\begin{array}{c}\text { Programmable Logic } \\
\text { Controller }\end{array}$ & SIMATIC S7-200 & Data processing and storage \\
\hline
\end{tabular}

\subsection{1 infrared temperature probe}

The infrared thermometer can calculate the surface temperature of the object by measuring the infrared radiation intensity emitted by the target without touching the target. Non-contact temperature measurement is the biggest advantage of the infrared thermometer. So that users can easily measure difficult to approach or move the target. The basic performance and measurement parameters of infrared temperature probe are shown in Table 3, Table 4.

Table 3. Basic Performance of Infrared Temperature Probe

\begin{tabular}{|c|c|c|c|c|c|}
\hline $\begin{array}{c}\text { Basic } \\
\text { performance }\end{array}$ & $\begin{array}{c}\text { Protection } \\
\text { level }\end{array}$ & $\begin{array}{c}\text { Ambient } \\
\text { temperature }\end{array}$ & $\begin{array}{c}\text { Storage } \\
\text { temperature }\end{array}$ & $\begin{array}{c}\text { Relative } \\
\text { humidity }\end{array}$ & Materials \\
\hline $\begin{array}{c}\text { Performance } \\
\text { description }\end{array}$ & I P65 & $0-60^{\circ} \mathrm{C}$ & $-20-80^{\circ} \mathrm{C}$ & $10-95 \%$ & Stainless Steel \\
\hline
\end{tabular}

Table 4. Measurement Parameters of Infrared Temperature Probe

\begin{tabular}{|c|c|c|c|c|c|c|c|}
\hline $\begin{array}{c}\text { Measurement } \\
\text { parameters }\end{array}$ & $\begin{array}{c}\text { Spectral } \\
\text { range }\end{array}$ & $\begin{array}{c}\text { Temperature } \\
\text { range }\end{array}$ & $\begin{array}{c}\text { Optical } \\
\text { resolution }\end{array}$ & $\begin{array}{c}\text { Response } \\
\text { time }\end{array}$ & $\begin{array}{c}\text { Measuring } \\
\text { accuracy }\end{array}$ & $\begin{array}{c}\text { Repeat } \\
\text { accuracy }\end{array}$ & Emissivity \\
\hline Parameters & $8-14 \mu \mathrm{m}$ & $0-500^{\circ} \mathrm{C}$ & $20: 1$ & $200 \mathrm{~ms}$ & $\pm 1^{\circ} \mathrm{C}$ & $\pm 1^{\circ} \mathrm{C}$ & 0.95 \\
\hline
\end{tabular}




\subsubsection{Programmable Logic Controller}

Programmable logic controller (PLC) is an industrial controller with CPU as the core, which integrates advanced technology such as computer and automatic control. PLC has many unique advantages, such as high reliability, perfect function, flexible combination, simple programming and low power consumption.[3] The CPU in the PLC is the core of the data processing sub-module, which plays the role of command. It is mainly used to run the user program, monitor the state of the input / output interface, and act as logical judgment and data processing.

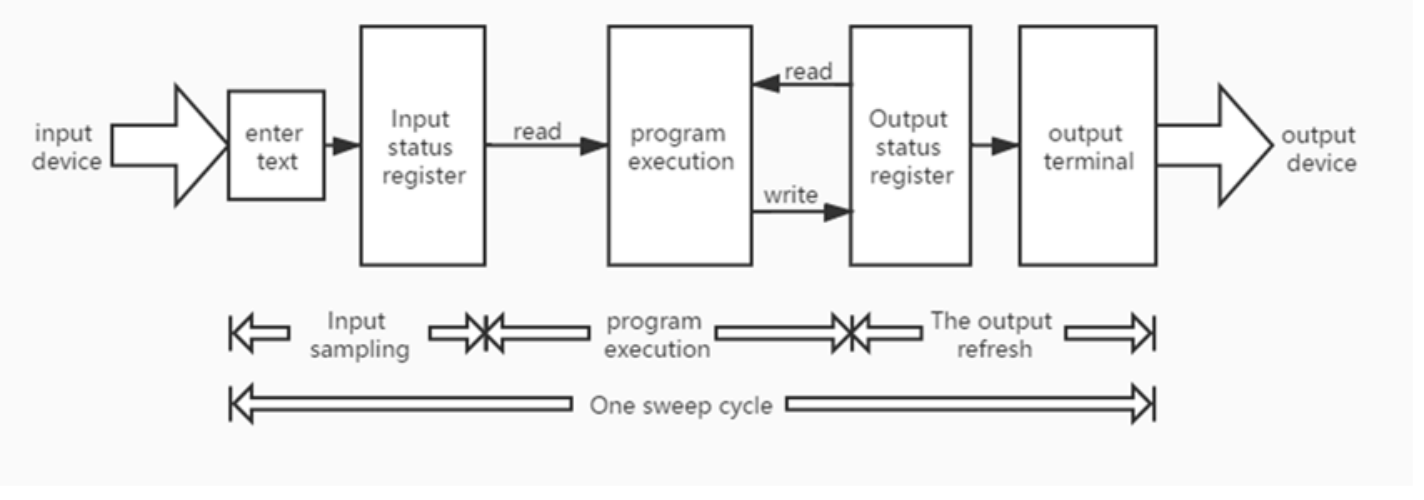

Figure 3. PLC Schematic illustration of the scanning process

\section{Summary}

The COVID-19 is highly infectious and it is very important to find and control the infected personnel in time. This paper analyzes and summarizes the advantages and disadvantages of body temperature measurement and collection system and its application occasions. In this paper, we designed a human temperature measurement and data collection system in order to realize more automatic and intelligent temperature measurement and collection during the COVID-19, which has the advantages of good economy and convenient non-contact temperature measurement data collection.

\section{References}

1. Cai Si, Men Xinlu, Wang Shan, Wang Ji, He Xiaoli, etc. A study on rapid and accurate measurement of body temperature of dense population during epidemic period of new coronavirus pneumonia [J]. Huaxi Medical Science ,2020,35(04):385-390.

2. Cai Si, Men Xinlu, Wang Shan, Wang Ji, He Xiaoli, etc. A study on rapid and accurate measurement of body temperature of dense population during epidemic period of new coronavirus pneumonia [J]. Huaxi Medical Science ,2020,35(04):385-390.

3. Qin Zenghuang. A Brief Course in Electrical Engineering Beijing: higher Education Press, China. 2015.3: 193 .

4. ISO standard 7730-84. Moderate thermal environments determination of PMV and PPD indices and specification of the condition for thermal comfort. International Standards Organization, Geneva, 1984.
5. Zhu yingxin. Architectural Environmental Science (second edition) [M] Beijing: China Construction Industry Press, 2009.

6. Chen Zheliang, Xue Fei, Wang Fulin. A novel control logic for fan coil unit considering both room temperature and humidity control $[\mathrm{J}]$, Build. Simulation. 8 (2015): 27-37.

7. Zhao Qianchuan, Yin, Zhao Yin, Wang Fulin et al. Preliminary study of learning individual thermal complaint behavior using one-class classifier for indoor environment control [J], Build. Environ. 72 (2014): 201-211.

8. Zhao Qianchuan, Cheng Zhijin, Wang Fulin et al. Experimental Assessment of a Satisfaction Based Thermal Comfort Control for a Group of Occupants [C], The IEEE International Conference on Automation Science and Engineering 2015, Gothenburg, Sweden, 2015. 